\title{
AÇÃO DE REGULADORES DE CRESCIMENTO NO PESO MEDIO DOS FRUTOS DE TOMATEIRO (Lycopersicon esculentum Mill.)*
}

\author{
PaUlo R. C. CASTRO** \\ JARÍ FerRI DA GUIA***
}

\begin{abstract}
RESUMO
Estudaram-se os efeitos da aplicação de sulfato de amônio e reguladores de crescimento no peso médio dos frutos de tomateiro (Lycopersicon esculentum Mill.) cultivares "Angela" e "Roma". Em dois ensaios ef etuou-se a aplicação de $\left(\mathrm{NH}_{1}\right)_{2} \mathrm{SO}_{4}(2 \mathrm{~g} / 1$ solo $)$, SADH $3000 \mathrm{ppm}, \mathrm{SADH}+\left(\mathrm{NH}_{1}\right)_{2} \mathrm{SO}_{4}, \mathrm{CCC} 2000 \mathrm{ppm}, \mathrm{CCC}$ $+\left(\mathrm{NH}_{4}\right)_{2} \mathrm{SO}_{4}, \mathrm{GA} 100 \mathrm{ppm}, \mathrm{GA}+\left(\mathrm{NH}_{4}\right)_{2} \mathrm{SO}_{4}$, além do tratamento controle. Em outros dois ensaios, além do controle, realizou-se a aplicação de 1-(2,4-diclorofenoxiacetil) -3,5- dimetil pirasol 3,75, 15,00 e 7,50 ppm, e de CEPA nas concentrações de 500,1000 e $1500 \mathrm{ppm}$. Verificou-se que o SADH promoveu redução no peso médio dos frutos dos tomateiros "Angela", em relação ao tratamento com $\left(\mathrm{NH}_{1}\right)_{2} \mathrm{SO}_{4}$. A incorporação de sulfato de amônio no solo restringiu os efeitos detrimentais da aplicação foliar de SADH. Pulverização com CCC, GA, Tomakon e CEPA não afetou o peso médio dos frutos das cultivares "Angela" e "Roma".
\end{abstract}

\section{INTRODUÇĀO}

E bastante conhecida a importância do tomateiro e o significado econômico da cultura dessa hortaliça; sendo que em 1972 a produção do Estado de São Paulo foi da ordem de $488.000 \mathrm{t}$.

A utilização de reguladores de crescimento no tomateiro é uma conseqüência da evolução das técnicas de cultivo que incluem irrigação, adubação, uso de defensivos e outras práticas agrícolas.

Os reguladores de crescimento têm sido empregados principalmente para induzir o florescimento, aumentar a fixação dos frutos e promover a maturação (WEAVER, 1972).

* Entregue para publicação em 23/06/1976.

* Departamento de Botânica. E.S.A. "Luiz de Queiroz" - USP.

** Estagiário Departamento de Botânica. E.S.A. "Luiz de Queiroz" - USP.

OBS.: Considerar aspas duplas referentes às cultivares como sendo aspas simples. 
A cultivar "Angela" tem demonstrado possuir boas características para a produção de tomate para a mesa, sendo que a cultivar "Roma" é das mais importantes na produção de tomate para industrialização.

O presente trabalho teve como finalidade verificar os efeitos da aplicação de reguladores de crescimento e sulfato de amônio no peso médio dos frutos de tomateiro.

\section{REVISÃO DA LITERATURA}

RASPEVIN (1963) aplicou giberelinas $100 \mathrm{ppm}$ em tomateiros 20 dias após a emergência, utilizando $5 \mathrm{ml}$ por planta. Observou $400 \%$ de precocidade e aumento no peso total dos frutos da ordem de $40 \%$. Verificou também melhoria na qualidade. Pulverização durante o florescimento aumentou o número de frutos, mas reduziu o peso médio dos mesmos. Tratamento com giberelinas em piantas que receberam insuficiente nutrição, causou deformação nos frutos produzidos.

MIRANDA NETO \& CHAVES (1969) verificaram aumento na precocidade de produção em tomateiros tratados com ácido giberélico (GA) 100 ppm e com GA 50 ppm + 50 ppm de ácido para-clorofenoxiacético; sendo que não foram observadas diferenças na produção total de frutos. Notaram ocorrência variável de frutos partenocárpicos; sendo que o peso médio dos frutos também apresentou variaçỗes diversas com a aplicação dos reguladores de crescimento. Observaram ainda uma tendência de diminuição no peso médio em consequeência de aumento no número de frutos.

SAWHNEY \& GREYSON (1971) verificaram, em condições de campo e de casa de vegetação, que o GA promove aumento no tamanho dos frutos de tomateiro. Observaram aproximadamente $50 \%$ de aumento no peso médio e no diâmetro dos frutos tratados com o regulador de crescimento.

CASTRO \& CHURATA-MASCA (1973) verificaram que a aplicação de cloreto de (2-cloroetil) trimetilamônio (CCC) na concentração de $4000 \mathrm{ppm}$, em irrigação, promoveu aumento no número de frutos por planta de tomateiro. Observaram que o peso total de frutos por planta também foi significativamente afetado, promovendo as maiores médias de produtividade as concentrações de $4000 \mathrm{ppm}$ em irrigação e $2000 \mathrm{ppm}$ sob a forma de pulverização. O peso médio dos frutos não foi afetado pelos tratamentos.

CASTRO (1976) observou que as plantas de tomateiro cultivar "Miguel Pereira" tratadas com CCC 2000 ppm e ácido (2-cloroetil) fosfônico (CEPA) 200 ppm não mostraram diferenças significativas no 
peso médio do fruto, em relação ao controle; sendo que tratamentos com ácido succínico -2,2- dimetilhidrazida (SADH) 3000 ppm e GA 200 ppm apresentaram redução no peso médio do fruto, com relação ao controle.

\section{MATERIAL E MÉTODOS}

Iniciaram-se os experimentos em 20 de julho de 1973, em condições de casa de vegetação, tendo-se efetuado a semeadura das cultivares "Angela" e "Roma" de tomateiro (Lycopersicon esculentum Mill.) em caixas de madeira com solo esterilizado.

Efetuou-se o transplante em 22/08/73 para vaso de cerâmica com 14 litros de capacidade contendo 12 litros de solo. No transplante colocaram-se três plântulas por vaso, tendo-se realizado o desbaste de duas delas em 12/09/73 a fim de uniformizar o experimento. Efetuaram-se os demais tratos culturais normais para a cultura do tomateiro.

O primeiro ensaio constou da aplicação, na cultivar "Angela", de $\left(\mathrm{NH}_{4}\right)_{2} \mathrm{SO}_{4}$ (sulfato de amônio), ácido succínico -2,2- dimetilhidrazida (SADH) $3000 \mathrm{ppm}, \mathrm{SADH} 3000 \mathrm{ppm}+\left(\mathrm{NH}_{4}\right)_{2} \mathrm{SO}_{4}$, cloreto de (2-cloroetil) trimetilamônio (CCC) $2000 \mathrm{ppm}, \mathrm{CCC} 2000 \mathrm{ppm}+\left(\mathrm{NH}_{4}\right)_{2} \mathrm{SO}_{4}$, ácido giberélico (GA) $100 \mathrm{ppm}, \mathrm{GA} 100 \mathrm{ppm}+\left(\mathrm{NH}_{4}\right)_{2} \mathrm{SO}_{4}$, além do tratamento controle. A aplicação de sulfato de amônio foi realizada em 24/09/73, pela incorporação de 2 gramas de $\left(\mathrm{NH}_{4}\right)_{2} \mathrm{SO}_{4}$ por litro de solo. Nesta mesma data efetuaram-se também as aplicações dos reguladores de crescimento, por pulverização, até que as folhas estivessem completamente molhadas.

O segundo ensaio constou da aplicação dos mesmos tratamentos, na mesma data, em plantas da cultivar "Roma".

No terceiro ensaio, além do tratamento controle, aplicou-se, na cultivar "Angela", o 1-(2,4-diclorofenoxiacetil) -3,5-dimetil pirasol, na forma do produto comercial Tomakon (Ikeda S.A.) nas concentrações de $3,75,15,00$ e 7,50 ppm, e o ácido (2-cloroetil) fosfônico (CEPA) nas dosagens de 500,1000 e $1500 \mathrm{ppm}$. A pulverização com Tomakon foi efetuada em 04/10/73, quando as flores do primeiro cacho encontravam-se entreabertas; sendo que a aplicação de CEPA foi realizada em $26 / 11 / 73$, quando cerca de $65 \%$ dos frutos do primeiro cacho achavam-se no estágio "de vez". As pulverizações foram dirigidas aos cachos.

O quarto ensaio constou da aplicação dos mesmos tratamentos, nas mesmas datas, em plantas da cultivar "Roma".

Em todos os ensaios utilizou-se o delineamento experimental inteiramente casualizadas com 5 repetições, tendo-se mantido uma planta 
por vaso por repetição. A comparação de médias foi realizada pelo teste de Tukey, calculando-se a diferença mínima significativa (D.M.S.) ao nível de $5 \%$ de probabilidade.

As colheitas foram efetuadas em $06 / 12 / 73,15 / 12 / 73,25 / 12 / 73$, 15/01/74 e $04 / 02 / 74$; sendo determinados o peso e o número de frutos, para a obtenção do peso médio dos frutos.

\section{RESULTADOS}

Tabela 1 - Análise de variância do efeito da aplicação de $\left(\mathrm{NH}_{4}\right)_{2} \mathrm{SO}_{4}$ e reguladores de crescimento no peso médio dos frutos (média em gramas) por planta de tomateiro, diferença mínima significativa e coeficiente de variaçã para o primeiro e segundo ensaios.

\begin{tabular}{lll}
\hline Tratamento & «Angela» & «Roma» \\
\hline \hline $\left.\mathrm{NH}_{4}\right)_{2} \mathrm{SO}_{4}$ & 53,5559 & 46,3639 \\
$\mathrm{SADH} 3000 \mathrm{ppm}$ & 34,6359 & 41,4180 \\
$\mathrm{SADH}+\left(\mathrm{NH}_{4}\right)_{2} \mathrm{SO}_{4}$ & 33,1839 & 36,2199 \\
$\mathrm{CCC} 2000 \mathrm{ppm}$ & 38,6279 & 46,4080 \\
$\mathrm{CCC}+\left(\mathrm{NH}_{4}\right)_{2} \mathrm{SO}_{4}$ & 46,6799 & 41,0920 \\
$\mathrm{GA} 100 \mathrm{ppm}$ & 42,0179 & 36,1959 \\
$\mathrm{GA}+\left(\mathrm{NH}_{4}\right)_{2} \mathrm{SO}_{4}$ & 38,1819 & 33,1960 \\
$\mathrm{CONTROLE}$ & 37,4000 & 42,1339 \\
\hline $\mathrm{TESTE} \mathrm{F}$ & $3,0533^{*}$ & 1,2583 \\
\hline TUKEY D.M.S. (5\%) & 17,6632 & 19,7332 \\
\hline C.V. (\%) & 21,2556 & 23,8390 \\
\hline
\end{tabular}

(*) Significativo ao nível de $5 \%$ de probabilidade 
Tabela 2 - Análise de variância do efeito da aplicação de reguladores de crescimento no peso médio dos frutos (média em gramas) por planta de tomateiro. diferença mínima significativa e coeficiente de variação, para o terceiro e quarto ensaios.

\begin{tabular}{lcc}
\hline Tratamento & «Angela» & «Roma» \\
\hline \hline & & \\
CONTROLE & 47,5799 & 44,7639 \\
TOMAKON $3,75 \mathrm{ppm}$ & 38,7379 & 40,9639 \\
TOMAKON $15,00 \mathrm{ppm}$ & 44,2219 & 41,1119 \\
TOMAKON $7,50 \mathrm{ppm}$ & 55,5680 & 36,2479 \\
CEPA 500 ppm & 46,3499 & 45,3779 \\
CEPA 1000 ppm & 39,9999 & 37,9019 \\
CEPA 1500 ppm & 43,4080 & 32,6239 \\
\hline TESTE F & & 1,5825 \\
\hline TUKEY D.M.S. (5\%) & 1,5292 & 16,3776 \\
\hline
\end{tabular}

\section{DISCUSSAO}

Pela tabela 1 verificou-se, através do teste $F$, a ocorrência de diferença significativa entre os tratamentos, no primeiro ensaio (cultivar "Angela"). O teste Tukey mostrou que o tratamento com $\left(\mathrm{NH}_{4}\right)_{2} \mathrm{SO}_{4}$ promoveu aumento no peso médio dos frutos de tomateiro em relação aos tratamentos com SADH $+\left(\mathrm{NH}_{4}\right)_{2} \mathrm{SO}_{4}$ e apenas SADH $3000 \mathrm{ppm}$. Deste modo verificou-se que a aplicação do retardador de crescimento mostrou-se prejudicial ao incremento no peso médio dos frutos, sendo que o tratamento com SADH $+\left(\mathrm{NH}_{4}\right)_{2} \mathrm{SO}_{4}$ revelou-se menos prejudicial em relação à aplicação de sulfato de amônio. Isto demonstra que a incorporação de $\left(\mathrm{NH}_{4}\right)_{2} \mathrm{SO}_{4}$ no solo pode restringir os efeitos detrimentais do SADH aplicado por via foliar, no peso médio dos frutos de tomateiro. CASTRO, (1976) também observou redução no peso médio do fruto de tomateiros tratados com SADH. E possível que o SADH afete o peso médio dos frutos de tomateiro por restringir a síntese de ácido indolacético endógeno (REED et alii 1965; RYUGO \& SACHS, 
1969) necessário aos processos de desenvolvimento; sendo que o $\left(\mathrm{NH}_{4}\right)_{2}$ $\mathrm{SO}_{4}$ pode reduzir sensivelmente esses efeitos por sua ação em promover elevação nos teores de aminoácidos livres nos frutos (HOFF et alii 1974) e assim possivelmente favorecer a síntese de fitohormônios.

No segundo ensaio (tabela 1) observou-se uma tendência do tratamento com GA $+\left(\mathrm{NH}_{4}\right)_{2} \mathrm{SO}_{4}$ promover redução no peso médio dos frutos da cultivar "Roma". Isto possivelmente se deve à aceleração no crescimento promovida pelo GA 100 ppm nesta cultivar de porte baixo, juntamente com o desenvolvimento adicional causado pelo sulfato de amônio. CASTRO (1976) verificou redução no peso médio do fruto de tomateiros pulverizados com GA.

Apesar de não se observarem diferenças estatísticas entre os tratamentos, verificamos pela tabela 2, que o tratamento com Tomakon $7,50 \mathrm{ppm}$ promoveu uma tendência de elevar o peso médio dos frutos da cultivar "Angela", no terceiro ensaio.

No quarto ensaio (tabela 2) notou-se uma ligeira tendência do tratamento com CEPA 500 ppm promover aumento no peso médio dos frutos da cultivar "Roma", principalmente em relação à aplicação de concentração mais elevada do produto (CEPA $1500 \mathrm{ppm}$ ).

\section{CONCLUSÕES}

Os resultados destes ensaios, permitem as seguintes conclusões:

1. O ácido succínico -2,2- dimetilhidrazida promove redução no peso médio dos frutos dos tomateiros cultivar "Angela" quando comparados com tomateiros adubados com sulfato de amônio.

2. A incorporação de sulfato de amônio no solo restringe os efeitos detrimentais do ácido succínico -2,2- dimetilhidrazida.

3. Aplicação de cloreto de (2-cloroetil) trimetilamônio, ácido giberélico, 1- (2,4-diclorofenoxiacetil) -3,5-dimetil pirasol e ácido (2-cloroetil) fosfônico não afeta o peso médio dos frutos de tomateiro.

\section{SUMMARY}

ACTION OF GROWTH REGULATORS ON THE WEIGHT AVERAGE OF FRUIT OF TOMATO (LYCOPERSICON ESCULETUM MILL.)

This research deals with the effect of $\left(\mathrm{NH}_{4}\right)_{2} \mathrm{SO}_{4}$ (ammonium sulphate) and exogenous growth regulators on weight average of fruit of tomato cultivars "Angela" and "Roma". 
In two experiments, $\left(\mathrm{NH}_{4}\right)_{2} \mathrm{SO}_{4}(2 \mathrm{~g} / 1$ soil), succinic acid -2,2- dimethylhydrazide (SADH) 3000 ppm, SADH plus $\left(\mathrm{NH}_{4}\right)_{2} \mathrm{SO}_{4}$, (2-chloroethyl) trimethylammonium chloride (CCC) $2000 \mathrm{ppm}, \mathrm{CCC}$ plus $\left(\mathrm{NH}_{4}\right)_{2} \mathrm{SO}_{4}$, gibberellic acid (GA) $100 \mathrm{ppm}$, GA plus $\left(\mathrm{NH}_{4}\right)_{2}$ $\mathrm{SO}_{4}$, and check treatment, were applicd. In two other experiments, 1-(2,4-dichlorophenoxyacathyl) -3,5-dimethyl pyrazole at concentrations of 3,75, 15,00 and 7,5 ppm, and (2-chloroethyl) phosphonic acid (CEPA) 500, 1000 and $1500 \mathrm{ppm}$, were used. It was observed that SADH promotes reduction in the weight average of fruit of tomato "Angela" in relation to treatment with $\left(\mathrm{NH}_{4}\right)_{2} \mathrm{SO}_{4}$. Ammonium sulphate in the soil reduced the detrimental effects of foliar application of SADH. Tomato plants "Angela" and "Roma" sprayed with CCC, GA, Tomakon and CEPA did not show variation in the weight average of fruit.

\section{LITERATURA CITADA}

CASTRO, P.R.C. 1976 - Efeitos de reguladores de crescimento em tomateiro (Lycopersicon esculentum Mill.). Tese de Doutoramento, Universidade de São Paulo, Piracicaba, 148 p.

CASTRO, P.R. C. ; CHURATA-MASCA, M. G.C. 1973 - Efeitos đu cloreto de 2-cloroetil trimetilamônio na produtividade do tomateiro. Supl. Ciência e Cultura 25(6) : 530.

HOFF, J.E.; WILCOX, G.E.; JONES, C.M. 1974 - The effect of nitrate and ammonium nitrogen on the free amino acid composition of tomato plants and tomato fruit. J. Amer. Soc. Hort. Sci. 99 (1) : 27-30.

MIRANDA NETO, A.T.; CHAVES, J.R.P. 1969 - Efeito da aplicação dos ácidos giberélico e paracloro-fenoxiacético em tomateiro. Rev. Ceres 16(89): 178-192.

RASPEVIN, J.A. 1963 - Changes in tomatoes under the influence of gibberellin. Vestn. Sel'sk. Nauki 8(12): 131-134.

REED, D.J.; MOORE, T.C.; ANDERSON, J.D. 1965 - Plant growth retardant B-995: A possible mode of action. Science 148: 1469-1471.

RYUGO, K. ; SACHS, R.M. 1969 - In vitro and in vivo studies of Alar (1,1-dimethylaminosuccinamic acid, B-995) and related substances. J. Amer. Soc. Hort. Sci. 94 : 529-533.

SAWHNEY, V.K. ; GREYSON, R.I. 1971 - Fruit size increase in tomato (Lycopersicon esculentum) through gibberellic acid treatment. Amer. J. Bot. 58: 460.

WEAVER, R.J. 1972 - Plant growth substances in agriculture. San Francisco, W. H. Freeman. $594 \mathrm{p}$. 
